\title{
De súbditos del rey a ejidatarios posrevolucionarios. Los subalternos en la historia de México: territorio, gobierno y resistencia
}

Hubonor Ayala Flores

Facultad de Historia

Universidad Veracruzana, México

hayala@uv.mx

Brehnis Daniel Xochihua García

Facultad de Historia

Universidad Veracruzana, México

dany_xochihua@hotmail.com

Michael T. Ducey y Luis Juventino García Ruíz (coords.), De súbditos del rey a ejidatarios posrevolucionarios. Los subalternos en la historia de México: territorio, gobierno y resistencia, Universidad Veracruzana, Xalapa, Ver., 2019.

La obra contribuye al entendimiento histórico de las comunidades rurales e indígenas de diferentes regiones de México a través de sus manifestaciones por la lucha de la tierra, la negociación política, así como la defensa del territorio. El título del libro es reflejo de algunos debates historiográficos que se han venido dando en las últimas décadas en el gremio de los historiadores y que tienen que ver con una variedad de aspectos políticos, económicos, culturales y sociales. El primero se refiere a la inserción de las nuevas formas de gobierno en el espacio Iberoamericano a partir de la crisis del Antiguo Régimen, proceso relacionado con las transformaciones derivadas de las ideas ilustradas primero, y el surgimiento del liberalismo después; así como con acontecimientos específicos como la revolución francesa y la independencia de los Estados Unidos de Norteamérica. En este sentido el título recuerda a otro conjunto de estudios que se publicó en el año 2000, titulado De súbditos del Rey a ciudadanos de la nación, que analizó precisamente esos procesos en el espacio 
Iberoamericano. El segundo debate tiene que ver con los estudios subalternos, propuesta metodológica que inicia con los aportes de los historiadores indios como Ranajit Guha y sus discípulos en la década de los ochenta, anclado a su vez con las propuestas de la historia desde abajo o la historia social inglesa. Estos estudios retomaron el papel de los sectores bajos, populares y subalternos de la sociedad, a quienes no se les había reconocido o más bien negado su participación e importancia en la construcción de los procesos histórico-sociales, pero sobre todo su capacidad de negociación, participación política, social y cultural.

Los escritos que se presentan en la obra abarcan una pluralidad de espacios y enfoques que dan cuenta del esfuerzo comparativo de procesos histórico-sociales que se desarrollaron en la Costa del Golfo, la Península de Yucatán, la región de Michoacán y el Estado de México y Oaxaca, por lo que la obra cubre de manera suficiente un amplio espacio de análisis de suma importancia para los estudios históricos de las poblaciones indígenas y rurales. Los mapas, cuadros y fotografías enriquecen cada uno de los capítulos, y constituyen una riqueza de información e interpretación histórica.

Otro aporte general de la obra es la amplitud de miradas, enfoques y fuentes utilizadas, pues si bien en el subtítulo se apuntan las categorías de territorio, gobierno y resistencia, el lector encontrará muchas otras como negociación política, transformaciones internas de las comunidades indígenas y rurales, estrategias de sobrevivencia, tensión entre tradición y modernidad, cambios en las estructuras corporativas, entre otros temas de análisis. Cada autor realizó un riguroso balance historiográfico la selección de fuentes documentales como las contenidas en el Archivo General de la Nación, los archivos estatales y municipales, de juzgados, notariales, cuerpos legales del periodo, fuentes hemerográficas, mapas, informes oficiales, entre otras. 
A lo largo de la obra se corrobora que los líderes y las comunidades rurales y campesinas no eran actores o grupos pasivos ante los procesos sociales, económicos y culturales que les tocó vivir a lo largo de diferentes periodos de la vida nacional. Tampoco eran comunidades estáticas, conservadoras o profundamente tradicionales. Por ejemplo, Luis Alberto Arrioja Díaz Viruel demuestra que las comunidades indígenas de Villa Alta, Oaxaca establecieron una serie de estrategias de adaptación a los cambios políticos desde la segunda mitad del siglo XVIII y hasta antes de la revolución de independencia; ya fuera integrando sus usos y costumbres, luchando por su autonomía política, o negociando con los diferentes órdenes de gobierno, lo que a final de cuentas repercutió en la multiplicación de las llamadas “repúblicas municipales”(p. 48) en la región.

José Luis Alcauter Guzmán analiza el régimen de subdelegaciones y cómo afectó en la República de indios esta reforma de la Real Ordenanza de Intendentes a finales del siglo XVIII en la región de Michoacán. La dinastía de los Borbones trató de administrar sus colonias en América con el objetivo de tener el mayor rendimiento económico posible, puesto que el escenario internacional del imperio demandaba tales cambios. En este capítulo se muestra el papel del subdelegado como representante del intendente en las provincias, con la facultad de intervenir en la autonomía del gobierno de las repúblicas de indios.

Por su parte, Paulo César López Romero aborda el espacio de la subdelegación de Xalapa y la territorialidad de los pueblos de indios a finales del periodo virreinal. El autor pone de relieve la importancia de la geografía, los recursos naturales, las comunicaciones y el clima como determinantes de las actividades productivas y de la vida de estos pueblos. Lo anterior generó pugnas y luchas por la tierra en la región mediante estrategias como la compra, renta o 
restitución de las mismas, todo lo anterior delineado por la negociación política y el uso de los marcos legales.

En otro capítulo del libro, Antonio Escobar Ohmstede realiza un estudio sobre la manera en que los pueblos de indios enfrentaron la individualización de los condueñazgos en la segunda mitad del siglo XIX en los Valles Centrales de Oaxaca, cambiando el paradigma en la tenencia de la tierra heredado del periodo colonial y la reacción de los individuos con esos cambios. El análisis se enfoca en el periodo de las reformas liberales y la aplicación de las leyes desamortizadoras en los pueblos oaxaqueños. Se asume que para el estado de Oaxaca es preciso referirse a "procesos desamortizadores" (p. 112), debido a las diversas formas en que se aplicaron estas leyes. A partir de esto, las relaciones entre habitantes y autoridades se fueron transformando y las relaciones familiares cambiaron por ciertas legislaciones gubernamentales respecto a la tenencia de la tierra, marcando una transición de la sociedad entre el final del siglo XIX y el inicio del siglo XX.

Otro espacio de análisis abordado en esta obra es la Sierra de Santa Marta, porción de tierra entre la Costa del Golfo de México, la Llanura Costera y la región del Istmo. Emilia Velázquez Hernández nos lleva a un interesante recorrido sobre las transformaciones y adaptaciones del uso de la tierra por parte de las comunidades indígenas de esta zona desde fines del siglo XIX hasta el fin del siglo XX. Procesos como la desamortización de tierras comunales, la fracción del territorio mediante el condueñazgo, el usufructo de tierras por parte de grandes compañías, así como el reparto agrario y la aparición del ejido afectaron las tierras comunales indígenas de la región. Todos estos procesos, concluye la autora, establecieron tensiones y conflictos al interior de las comunidades indígenas, habitualmente vistas como 
unívocas y monolíticas, además hay que diferenciar entre acceso y propiedad de la tierra, pues en el caso de su estudio, se conjugaron al mismo tiempo.

Abel Juárez analiza un tumulto en Acayucan, Veracruz en 1787, un caso muy interesante, puesto que fue "instigado por una influyente mujer de la localidad" (p. 167). Y otro rasgo fue que los vecinos del pueblo manifestaron su descontento hacia los poderes virreinales, lo que llevó a la movilización de la milicia para apaciguar el tumulto. En este estudio se muestra la manera de solucionar este tipo de conflictos por parte de ambos bandos en un periodo de tensión para la Corona española. El autor corrobora la facilidad con que algunos lugares alejados de la capital virreinal podían levantarse en defensa de sus intereses y cómo la mujer no siempre desempeñó un papel abnegado en esta época.

La guerra popular y la insurgencia en la Costa de Barlovento en pleno proceso de la lucha de independencia, entre 1814 y 1820 es el amplio estudio presentado por Michael Ducey. Interesado en el "modo en que los pueblos experimentaron la guerra” (p. 186) Ducey reflexiona sobre la importancia del dominio del territorio, la estructura de su organización social y la cosmovisión; elementos que hicieron posible el sostenimiento de la insurgencia en años tan difíciles para el movimiento independentista. La forma de hacer la guerra estuvo determinada por el desplazamiento de las poblaciones rebeldes a “cantones” ubicados en zonas de difícil acceso para las tropas regulares realistas, la implementación de las guerrillas como forma predilecta de lucha y el uso de fortificaciones temporales. Las comunidades insurgentes de Barlovento utilizaron el conocimiento y dominio del terreno a su favor para diezmar al enemigo, con la estrategia de "huir y emboscar", actuaron en conjunto de acuerdo a sus estructuras comunitarias, plantearon como prioridad la preservación de la vida de sus 
miembros y utilizaron los pocos elementos a su favor como estrategias de sobrevivencia y éxito en esos aciagos años.

La repercusión de la guerra de independencia entre los indios realistas en Xalapa es abordado por Luis Juventino García Ruíz, quien reflexiona sobre los diferentes factores que afectaron la vida de la sociedad novohispana durante el proceso de la Guerra de Independencia: organización social, militarización, reconfiguraciones territoriales, representación política entre otros factores. La amplia participación indígena en este movimiento determinó también esta serie de cambios y en el caso particular de Xalapa, les permitió “(...) transformar las condiciones políticas, sociales y económicas que tenían a principios del siglo XIX” (p. 225). Lo anterior generó un cambio de su estatus jurídico-político y una mayor preminencia político-social a través de su incorporación y participación en la milicia realista, que se tradujo en mayores ventajas como el acceso al fuero militar, el indulto tributario, así como la posibilidad de establecer formas corporativas de asociación. García Ruíz reflexiona que los indios realistas salieron favorecidos como corporación, preservaron su forma de autogobierno y representación territorial ante el ayuntamiento de españoles, recuperaron parte de sus tierras comunales y fortalecieron su identidad étnica.

Otra perspectiva sobre la Oaxaca porfiriana la realiza Juan Hugo Sánchez García, quien aborda la cárcel de la ciudad de Oaxaca y su proceso de modernización; establece este espacio como contenedor de población de origen rural e identifica las tensiones entre la tradición y la modernidad en este espacio carcelario. El estudio también identifica el papel de los presos y su participación en la construcción de las obras de la ciudad y pone de manifiesto la presencia del entorno y la población rural en los espacios públicos. Los resultados de esta investigación manifiestan las dificultades para afirmar el éxito de una modernización penal y carcelaria. 
Por su parte, Terry Rugeley realiza un sugerente ensayo en el que analiza las transiciones de la cultura maya en un largo periodo de tiempo que va desde fines del periodo virreinal hasta el presente. El autor analiza paso a paso las transformaciones de la población de origen maya a través de diferentes procesos históricos que marcaron la vida de la región como la Guerra de Castas, la Revolución y las transformaciones económicas del siglo XX, que han generado en la actualidad “(...) una sociedad moldeada por valores globales y no por las encantadoras costumbres de un pequeño pueblo” (p. 317). 